\title{
METEORITES IN METEORITES: EVIDENCE FOR MIXING AMONG THE ASTEROIDS
}

\author{
L. L. WILKENING
}

Inclusions of one type of meteorite enclosed in another have been found in several gas rich meteorites, unequilibrated chondrites and mesosiderites. The inclusions in all but one case are chondritic; a majority are mineralogically and isotopically similar to carbonaceous chondrites. These meteorite mixtures most probably resulted from collisions among asteroids.

\section{INTRODUCTION}

The purpose of this paper is, first, to review some examples of mixtures of two meteorite types in a single meteorite and, secondly, to discuss the implications of these observations for the meteorite parent bodies.

Most stony meteorites are breccias which were formed by repeated cycles of comminution, mixing and compaction. These processes were most probably a result of impacts in regoliths on the surfaces of the parent planets of the meteorites. The strongest evidence for the role played by these processes is found in the gas-rich meteorites which have brecciated textures, solar-wind gases, solar particle tracks, and micrometeorite craters. Many non-gas-rich stony meteorites show textural evidence of comminution, mixing and compaction precesses as well. Textural evidence is most striking in achondrites, LL-group chondrites and shocked L-group chondrites.

Another feature of formation in a surficial regolith is the presence of foreign or exotic material in meteorites. As observed the foreign matter consists of mm-to-cm-sized fragments, which are referred to as inclusions or xenoliths. The fragments are embedded in another type of meteorite, referred to as the host.

Examples of meteorite mixtures have been known for some time. One of the most striking examples was described in 1920 by Merri11. It is the Cumberland Falls aubrite in which dark chondritic matter is enclosed in the white, enstatite achondrite host. Cumberland Falls is unique in being a mixture of black and white components on a cm-scale. Since other meteorite mixtures are not so obvious, the consensus among meteoricists has been that very 1 ittle mixing has taken place among different classes of meteoritic matter. The fact that the chemical compositions of the E, H, L, LI, and $C$ chondrites fall in discrete clusters rather than forming a continum in major element composition (Mg, Fe, $\mathrm{Si})$ is the argument most often cited against mixing. However, since analysists select samples from "typical" or "representative" portions of meteorites, there is a bias in the chemical data against exotic materials. In any case, small, 
rare inclusions whose composition is not very different (e.g., iron contents of $H$ and $L$ group differ from one another by 6 wt ; CM's and L's have essentially the same total iron content) from the host may well not perturb the average major element composition out of the cluster in which the host meteorite belongs. Thus, it is quite possible that the abundance of foreign inclusions in meteorites (heretofore considered to be close to zero) has been underestimated.

\section{EXAMPLES OF METEORITES IN METEORITES}

In Figure 1 are photographs of foreign inclusions in four different meteorites. In each case the inclusion is of carbonaceous type, apparentIy CI or CN. The host meteorites include an achondrite, a $\mathrm{CV}$ - and two H-group chondrites.

A summary of examples of meteorite mixtures taken from the 1 iterature and from our unpublished work is given in Table $I$. In this table the symbols immediately following the meteorite name denote the classification of the host. The symbols in parentheses denote the classification of the inclusion or inclusions. The symbols C, H, L, LL and E refer to chondrites, the most abundant meteorites. Au stands for aubrite or enstatite achondrite, Ho for howardite, a basaltic achondrite. M stands for mesosiderite, a type of stony-iron meteorite. In the case of the inclusions, it has not always been possible to classify them completely. Hence, Ch indicates only that the inclusion seems similar to chondrites and $C$ that the inclusion is similar to carbonaceous chondrites. If there is sufficient evidence the carbonaceous chondrites are given their usual designation: (in the Wasson system) as CI, CM, CV or CO. These latter designations are equivalent to $\mathrm{C} 1, \mathrm{C} 2, \mathrm{C} 3 \mathrm{~V}$, and $\mathrm{C} 30$, respectively in the Van schmus and Wood system.

TABLE I

METEORITE MIXTURES

Abbott H5 (CM) Fodor et al. (1976)

Bencubbin M (Ch) McCall (1973)

Bremervörde H3 (C) Van Schmus (1967)

Cumberland Falls AU (Ch) Merrill (1920)

Cynthiana L4 (C) Van Schmus (1967)

Dimmit H3,4 (C) Fodor \& Keil (pers, comm.)

Holyoke $\mathrm{H} 4$ (CM) McCal1 (1973)

Jodzie Ho (CM) Bunch (1975)

Kapoeta Ho (CM) Wilkening (1973)

Lance $\mathrm{CO3}$ (CM) Kurat (1975)

Leighton H5 (CM) Wilkening (1976)
Leoville CV3 (CM) Keil et a1. (1968) Mezö-Madaras L3 (CM) Van Schmus (1967) Murchison CM (CO - CV) Fuchs et al. (1973) Plainview H5 (CM) Wilkening \& Clayton (1974) Pultusk H5 (C) Wilkening unpub. Sharps H3 (CM) Fredriksson et al. (1968) St. Mesmin LL6 (H6) Dodd (1974) Tennasilm L4 (C) Van Schmus (1967) Tieschitz H3 (C) Kurat (1970) Tynes Island $H 4$ (C) Wilkening unpu's. Weatherford M (Au \& C3) Mason \& Nelen (1968)

It is apparent that a variety of mixtures has been observed, also that carbonaceous chondrites are the most prevalent type among the inclusions studied so far. Among the host types, unequilibrated ordinary chondrites (H3, H4, L3, L4) are rather common. The remainder of the stony meteorites hosts are gas-rich, i.e.. surface breccias. The mesosiderite, Bencubbin, also seems to be an impact breccia according to McCall (1973). Both unequilibrated chondrites and the various gas-rich meteorites are known to have experienced little or no thermal metamorphism since their compaction. The apparent absence of xenoliths from some of the other types of meteorites could conceivably be due to post-compaction metamorphism which resulted in obliteration of small inclusions. Alternatively, inclusions may not have been introduced into these meteorites at all. 


\section{METEORITES IN METEORITES}
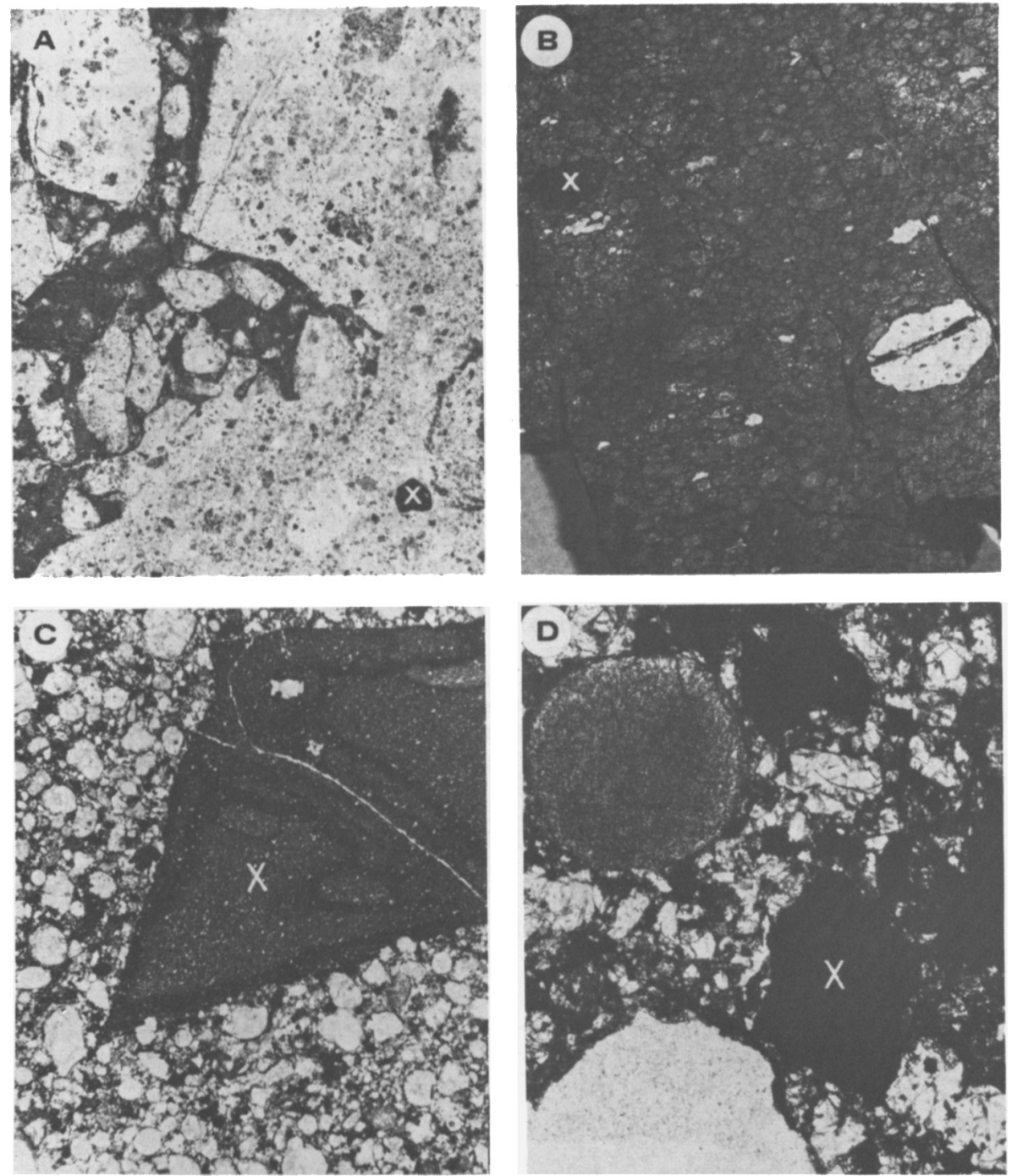

Figure 1. All xenoliths are marked with an $x$.

a) This is the brecciated basaltic achondrite, Kapceta, in which a small, mm-sized black, carbonaceous inclusion is visible. Field of view is about $3 \mathrm{~cm}$, greatest dimension.

b) This is a slide of Leoville which is a $\mathrm{CV}$ meteorite and contains the light-colored, high temperature condensate minerals found in this type of carbonaceous chondrite. Less conspicuous is an angular carbonaceous (CM) inclusion.

c) This photomicrograph of a thin section of an unequilibrated H-group chondrite, Sharps, shows about half of an angular carbonaceous fragment, which is in total about $1 \mathrm{~cm}$ long.

d) This photomicrograph shows another carbonaceous inclusion $1 \mathrm{~mm}$ long in a thin-section of the gas-rich, H-group chondrite plainview. 


\section{CHARACTERIZATION OF THE FOREIGN INCLUSIONS}

Somewhat more is known about the mineralogy and petrology of foreign inclusions that is known about any other aspect. Noble gases have been reported for three inclusions, oxygen isotopes for one and trace elements in none. It should be noted at this point that in addition to the $\mathrm{Ca}$, Al-rich inclusions, which are not included in this discussion because they are not a type of meteorite, some other "achondritic" inclusions in chondrites have been reported.

TABLE II

SUMMARY OF MINERALOGY OF CARBONACEOUS INCLUSIONS

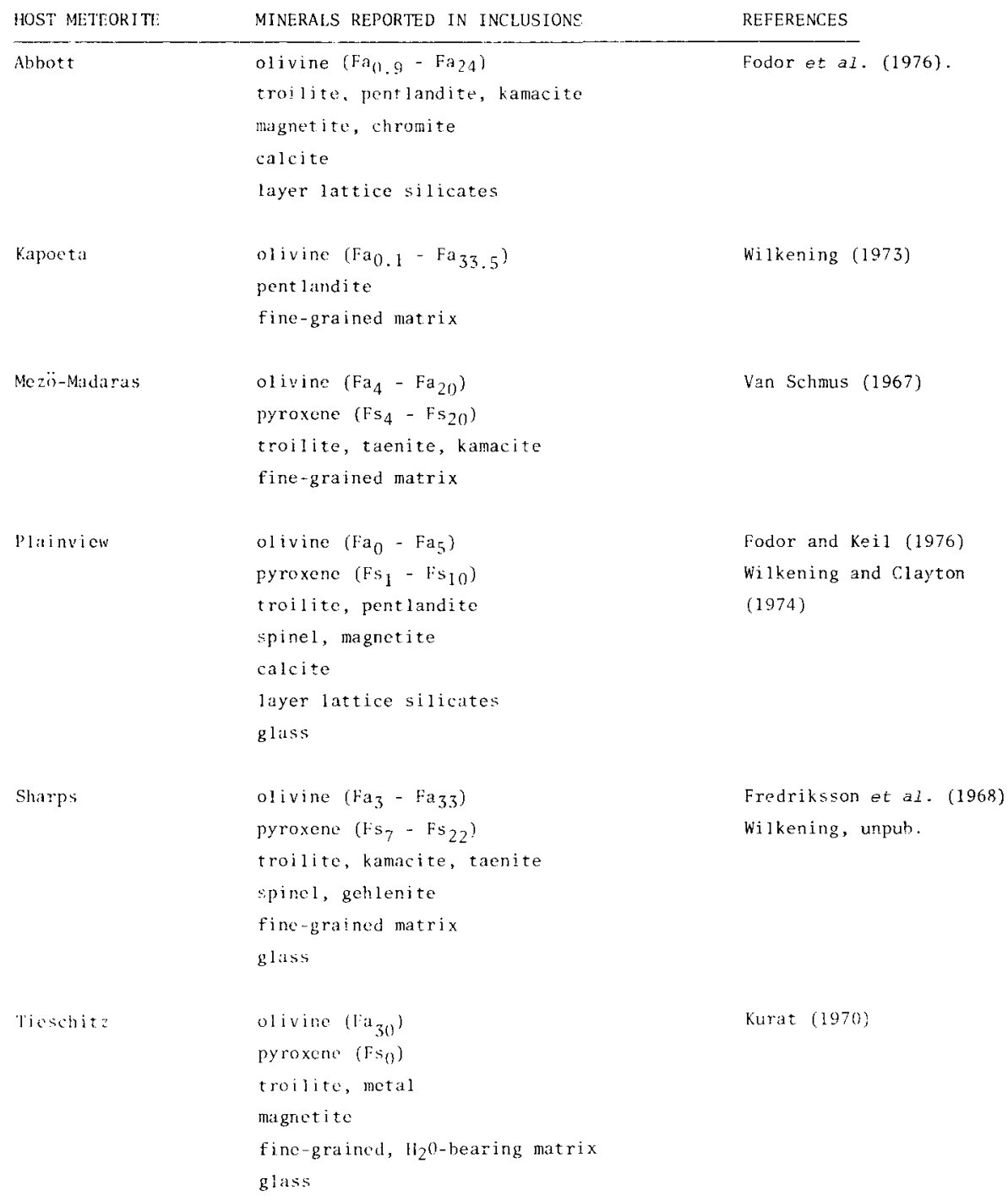


Thorough investigation of achondritic inclusions in Plainview (Fodor and Keil 1976), Abbott (Fodor et al. 1976) and other meteorites (Fodor, Keil, and Jarosewich 1972; Fodor and Keil 1975) have shown that the "achondritic inclusions" are chemically related to the host meteorites and were probably formed by impact melting and/or metamorphism of host material.

Mineralogical observations on six of the more thoroughly studied carbonaceous xenoliths are summarized in Table II. Mineralogical features diagnostic of carbonaceous chondrites include (1) a marked predominance of low-Fe over high-Fe compositions among olivines and pyroxenes (2) Ni-bearing sulfides (3) layer-lattice silicates (4) occurrence of one or more of calcite, magnetite, or gehlenite, perovskite (or other of the high $\mathrm{Ca}$, Al minerals found in high temperature condensates).

Wood (1967a) studied the olivine and pyroxene compositions in 10 CM chondrites. He found their compositions to be characterized by a wide range of iron compositions with distributions strongly peaked at low-iron compositions, e.g., olivine peaked sharply at 0.6-2 mole \% fayalite. Such distributions are characteristic $\mathrm{CI}$ and $\mathrm{CM}$ but not of other types of chondrites. The inclusions in Sharps, Mezö-Madaras, Plainview, Abbott and Kapoeta exhibit a wide range of olivine and/or pyroxene compositions. High frequencies of low-iron compositions were noted for Abbott, Plainview, Kapoeta, and Tieschitz (only low-iron compositions were found in the 2 silicate fragments present).

Wood (1967) pointed out that CM chondrites are characterized by the disequilibrium assemblage, kamacite-troilite-pentlandite whereas $C V$ and CO chondrites are characterized by either kamacite-taenite-troilite or taerite-troilitepentlandite. By these criteria the inclusions in Mezö-Madaras and Sharps should be $C V$ or $C O$, inclusions in Plainview and Abbott fall in the CM category. Not enough information is available for the others to apply this test. Although the mineralogy of the limited set of inclusions firmly establishes them as similar to carbonaceous chondrites, they are not identical to one another, some resembling more strongly one subtype than another and some, e.g., Mezö-Madaras, evidently having characteristics of two different subtypes. Curiously, some inclusions such as the one in Sharps are devoid of chondrules.

TABLE III

ANALYSES* OF MATRIX IN CARBONACEOUS INCLUSIONS

\begin{tabular}{|c|c|c|c|c|c|c|c|c|c|}
\hline & $\mathrm{SiO}_{2}$ & $\mathrm{Al}_{2}{ }^{\mathrm{O}} 3$ & $\mathrm{FeO}$ & $\mathrm{NiO}$ & $\mathrm{MgO}$ & $\mathrm{CaO}$ & $\mathrm{Na}_{2} \mathrm{O}$ & $S$ & C \\
\hline $\begin{array}{l}\text { Abbott } \\
(\# 10)\end{array}$ & 30.4 & 2.9 & 27.3 & --- & 19.0 & 0.43 & 0.05 & $(1.5)^{\star}$ & $(1.8)^{*}$ \\
\hline $\begin{array}{l}\text { Plainview } \\
\text { (PV6) }\end{array}$ & 33.7 & 2.6 & 20.3 & 1.0 & 25.8 & 0.5 & 0.1 & 0.7 & --- \\
\hline Sharps & 28 & 2.9 & 39 & 1.6 & 22 & 0.8 & 0.3 & 0.4 & -5 \\
\hline $\begin{array}{l}\text { Tieschitz } \\
\text { (Mean of } 7 \text { analyses) }\end{array}$ & 30.7 & 1.9 & 36.1 & 0.4 & 13.2 & 1.7 & 1.2 & .04 & 5.2 \\
\hline Leighton & 27.4 & 1.3 & 23.9 & $\ldots$ & 18.4 & 0.6 & $\cdots-$ & --- & --- \\
\hline
\end{tabular}

Mezö-Madaras

*All Fe and $\mathrm{Ni}$ calculated as the oxides. All data taken from references given in Table II. 
Most investigators have tried to obtain a bulk analysis of the finegrained matrix which is always the major constituent of these inclusions. Such analyses are usually made by defocussed beam analys is using an electron probe microanalyzer. Typical results are given in Table III. The analyses vary widely and it is difficult to attach much meaning to them at present. The consistently high estimates of carbon concentrations are one notable feature of such analyses. The median carbon content of CI chondrites is 3.1 wt.\% with a maximum observed value of $4.8 \mathrm{wt} . \%$; other types have lower concentrations (Mason 1971). Unfortunately, the highest concentrations in the xenoliths were determined by inaccurate probe methods, so their significance is not clear.

Oxygen isotopes and noble gases were measured by wilkening and Clayton (1974) in a single carbonaceous fragment from plainview. The results of both analyses showed the inclusion (PV6) to be indistinguishable from CM chondrites. Similar conclusions were drawn on the basis of the noble gas data obtained for one inclusion in Abbott. However, a second carbonaceous inclusion from Abbott was devoid of the noble gases characteristic of carbonaceous chondrites despite the minerological similarities of the two samples (Fodor et al. 1976). Fodor and co-workers suggest that a mild metamorphic event may account for the observed differences.

Sumnarizing the characteristics of the inclusions, it seems that a fraction of the inclusions studied are similar in several respect to carbonaceous chondrites. Trace element analyses of these fragments might yield further insight into their identity.

\section{ORIGIN OF THE METEORITES' IN METEORITES}

In the following discussion the assumption is made that meteorites come from the inner solar system. For a justification of this assumption, the reader is referred to Anders (1975). The essence of the argument is that the amounts of solar wind gases present in brecciated meteorites places the formation location inside the orbit of Jupiter. About half of the meteorites which contain foreign inclusions also contain solar wind.

The meteorites in meteorites could conceivably come from any one of, or combinations of, several sources. Attention is focussed here on the three sources which seem most plausible. (1) The inclusions could be material from another region of the same parent body. (2) The inclusions could be cometary debris intercepted by the parent planet. (3) The inclusions could have resulted from collisions among asteroidal objects. Other, more exotic origins for the inclusions will not be discussed here. Most seem rather unlikely in view of the demonstrated similarities in mineralogy and isotopic compositions between the inclusions and known meteorites.

Let us turn to a brief discussion of each of the aforementioned possibilities. First, the possibility that the xenoliths are from different portions of an inhomogeneous parent body is usually discussed in terms of vertical mixing. Vertical mixing between a carbonaceous chondritic layer or, in some cases, an ordinary chondritic layer, and various other host types could produce most of the observed mixtures. It has been pointed out many times that the different host materials such as howardites, aubrites and the ordinary chondrites could not have evolved for chemical reasons in contact with carbonaceous chondritic matter. This means the carbonaceous chondritic matter would have to have been deposited on the parent body surface following the chemical evolution of the parent.

This brings us to the second alternative, that cometary debris is the source of the included meteorites. Here the main problem seems to be the high relative velocities of the projectile and target. A good example of the problem is found on the lunar surface. From chemical analyses we know that the lunar soil is composed of $1-2 \%$ of matter contributed by primitive meteoroids. Never- 
theless, despite the particle by particle examination to which the soil has been subjected, only 4 or 5 actual meteorite fragments of any size have been recovered. Evidently, most of the projectiles were destroyed on impact. Hence, it seems that cometary debris is not likely to be responsible for a large share of the meteorites in meteorites.

Finally, we turn to collisions of asteroidal debris with other asteroids. Such collisions seem to satisfy the necessity for low relative velocities. Furthermore, the known variety of objects in the asteroid belt and a predominance of carbonaceous surfaces seem capable of producing the observed meteorite mixtures. Hence, it seems that we have records of asteroidal collisions in the meteorites.

\section{ACKNOWLEDGEMENT}

I am very grateful to John Wasson for reading this paper at Lyon. This work was supported by NASA Grant NSF 7011.

\section{REFERENCES}

Anders, E. 1975, Icarus, 24, 363-371.

Bunch, T. E. 1975, Proc. 6th Lunar Sci. Conf., Geochim. Cosmochim. Acta Supp. 6, vol. 1, 469-692.

Dodd, R. T. 1974, Contr. Mineral. and Petrol. 46, $129-145$.

Fodor, R. V., and Keil, K. 1975, Meteoritics, 10, 325-339.

Fodor, R. V., and Keil, K. 1976, Geochim. Cosmochim. Acta, 40, 177-190.

Fodor, R. V., Kei1, K., and Jaresowich, E. 1972, Meteoritics, 7, 495-507.

Fodor, R. V., Keil, K., Wilkening, L. L., Bogard, D. D., and Gibson, E. K. 1976, Tectonics \& Mineral Resource of Southwestern New Mexico; New Mex. Geol. Soc. Spec. Pub. \#6, 206-218.

Fredriksson, K., Jarosewich, E., and Nelen, J. 1968, Meteorite Research, P. M. Millman, ed.; D. Reidel Pub. Co., 155-165.

Fuchs, J. H., O1sen, E., and Jensen, K. J. 1973, Smithsonian. Contrib. to the Earth Sciences \#10.

Keil, K., Huss, G. I., and Wiik, H. B. 1968, Meteorite Research, P. M. Millman, ed.; D. Reidel Pub. Co., p. 217.

Kurat, G. 1970, Earth Planet. Sci. Lett., 7, 317-324.

Kurat, G. 1975, Tschermaks Min. Petr. Mitt., 22, 38-78.

Mason, B. 1971, Handbook of Elemental Abundances in Meteorites, Gordon and Breach, NY; $549 \mathrm{pp}$.

Mason, B., and Nelen, J. 1968, Geochim. Cosmochim. Acta, 32, 661-664.

McCal1, G. J. 1973, Meteorites and Their origins, Wiley \& Sons, NY; 352 pp.

Merri11, G. P. 1920, Proc. U.S. Nat. Mus., 57, 97-105.

Van Schmus, W. R. 1967, Geochim. Cosmochim. Acta, 31, 2027-2042.

Wilkening, L. L. 1973, Geochim. Cosmochim. Acta, 37, 1985-1989.

Wilkening, L. L. 1976, Proc. 7th Lunar Sci. Conf., in press.

Wilkening, L. L., and Clayton, R. N. 1974, Geochim. Cosmochim. Acta, 38, 937945 .

Wood, J. A. 1967a, Geochim. Cosmochim. Acta, 31, 2095-2108.

Wood, J. A. $1967 \mathrm{~b}$ Icarus, 6, I-49.

\section{DISCUSSION}

WHIPPLE: The differences among ages of meteorite matrices and their inclusions can provide a vital piece of information, namely, the distribution function of 


\section{WILKENING}

the time intervals of asteroidal breakup and reassembly. This function would tell about the rates of asteroidal breakup and growth as a function of time.

PAPANASTASSIOU: We have measured $R b-S r$ and $K-A r$ ages for three igneous basaltic clasts in Kapoeta. These yield ages of 4.5, 3.9, and 3.6 AE; these data have been interpreted as indicating extended magmatic activity on the parent planet for I $A E$ after formation at $4.6 \mathrm{AE}$. In addition, a "dark fragment" in kapoeta in which fission Xe from $244 \mathrm{Pu}$ was found some years ago by Rowe, was dated by $K-A r$ and is $4.5 \mathrm{AE}$ old. This "dark" fragment was identified as a basalt vitrophyre, by extensive petrographic and mineralogic work. Kapoeta is one of the meteorites in which Dr. Wilkening had identified a carbonaceous meteorite clast.

ANDERS: Wilkening's work puts an important constraint on the origin of ordinary chondrites. They must come from a region where $\mathrm{c} 2$ chondrite material is dominant As has become increasingly clear in the last few years, the asteroid belt is one such place.

KING: It may be that there is some bias in the recognition of lithic inclusions in meteorites in favor of the dark inclusions because they are easu to see. In my experience lithic inclusions (of either possibly related inclusions or dissimilar inclusions) are rather common in ordinary chondrites. These lightcolored inclusions have not been well-studied and are much less easy to recognize 